\title{
Influences of varying host: parasitoid ratios on parasitism of whitefly by three different parasitoid species
}

\author{
Li Lin ${ }^{1,2}$, Shaukat Ali ${ }^{1}$ and Jianhui $\mathrm{Wu}^{1^{*}}$
}

\begin{abstract}
This study reports the effects of different host: parasitoid ratios on parasitic behavior and functional response of three different parasitoid species (Eretmocerus sp. nr. furuhashii, Encarsia bimaculata, and Encarsia sophia) attacking the sweetpotato whitefly, Bemisia tabaci, under laboratory conditions. The parasitic ability of three parasitoid species was significantly influenced by the whitefly density. Increasing host density had beneficial effect on parasite efficiency of Er. sp. nr. furuhashii, E. bimaculata, and E. sophia. The rate of instant attack (a) observed for Er. sp. nr. furuhashii, E. bimaculata, and E. sophia was $0.1649,0.1113$, and 0.0655 , respectively. Total parasitic time $\left(T_{h}\right)$ observed for Er. sp. $\mathrm{nr}$. furuhashii, E. bimaculata, and E. sophia was 0.0737, 0.2325, and 0.1936, respectively. In the second experiment, the parasitical action was also influenced by parasitoid density. At constant host density, the rate of parasitism increased with parasite density up to a certain density followed by a decrease in rate of parasitism with increasing parasitoid density.
\end{abstract}

Keywords: Bemisia tabaci, Parasitoids, Density, Interference

\section{Background}

The sweet potato whitefly Bemisia tabaci (Gennadius) (Hemiptera: Aleyrodidae) is a serious pest of agricultural crops in different regions of the world (De Barro et al. 2011; Barbosa et al. 2014). From the 1980s, B. tabaci Middle East-Asia Minor 1 (MEAM1) cryptic species (previously known as "B biotype") has drastically increased in distribution. This has been attributed to the development and increase in global trade. Direct damage by $B$. tabaci occurs as a result of sucking plant sap from the phloem and secretion of honey dew which serves as a substrate for growth of sooty molds (Oliveira et al. 2001; Perring 2001). In addition, adults can transmit more than 150 plant viruses to commercial crops. Management of B. tabaci has been dominated by the frequent use of broad spectrum conventional chemical pesticides (Wang et al. 2010; Liang et al. 2012). The consistent use of synthetic chemicals for $B$. tabaci

\footnotetext{
* Correspondence: jhw@scau.edu.cn

${ }^{1}$ Key Laboratory of Bio-Pesticide Innovation and Application, Engineering Research Center of Biological Control, South China Agricultural University, Guangzhou 510640, People's Republic of China

Full list of author information is available at the end of the article
}

management has resulted in environmental pollution and adverse effects on humans, mammals, and other non-target organisms. This injudicious use of chemicals leads to the intermission of natural biological control systems and outbreaks of B. tabaci (Devine and Furlong 2007). All these factors have necessitated research and development of environmentally secure, biodegradable, and indigenous methods for insect pest management (Revathi et al. 2014). Hence, the search for effective naturally occurring biological control agents (predators or parasitoids) can be used as a potential method to overcome environmental pollution and resistance problems.

Parasitoids have been used extensively as a model system in studies of population and behavioral ecology, partially due to their potential use in biological pest control (Godfray and Shimada 1999). Parasitic wasp species belonging to genus Eretmocerus and genus Encarsia (Hymenoptera: Aphelinidae) are well known parasitoids of Bemisia tabaci (Gennadius) (Hemiptera:Aleyrodidae), with a widespread distribution worldwide (Qiu et al. 2003). These species are recognized as one of the most important natural enemies of $B$. tabaci having generated a lot of interest in countries where $B$. tabaci is a 
problem. They oviposit under the host and develop in a vital capsule within the host (Gerling et al. 1991). Adult parasitoids preferentially oviposit within the third and fourth instar nymph of whitefly, and the greatest rate of development occurs when the third instar whitefly nymphs are parasitized (Roudrigues et al. 1994; Gerling and Fried 2000; Kirk et al. 2000).

Any method targeted at enhancing the impact of parasitoids will depend on our knowledge of many factors, including interactions between parasitoid and host. However, quantitative data on host-parasitoid interactions for genus Eretmocerus and Encarsia are limited. The level of mortality inflicted on a host population is determined primarily by the response of the parasitoid to host density, while population stability is maintained as a result of both density-dependent parasitoid progeny production and parasitoid-inflicted host mortality (Holling 1959). To improve biological control of whiteflies and to obtain a better understanding of host-parasitoid interactions, detailed laboratory studies are necessary. Our previous studies have shown that Eretmocerus sp. nr. furuhashii, Encarsia bimaculata, and Encarsia sophia are the dominant parasitoids of Bemisia tabaci in China. The objectives of this study were to measure the response of Eretmocerus sp. nr. furuhashii, Encarsia bimaculata, and Encarsia sophia to varying B. tabaci densities, and the effects of parasitoid density on parasitic behavior and functional response.

\section{Materials and methods Materials \\ Plants}

Hibiscus rosa-sinensis L. branches (15 $\mathrm{cm}$ long) having two to three sprouting buds were cut from the stock plants grown at Engineering Research Center of Biological Control, Ministry of Education, South China Agricultural University, Guangzhou, China. The base of cuttings was dipped in indoleacetic acid solution $(5 \mathrm{~g} / \mathrm{L})$ for $1 \mathrm{~min}$ followed by planting in the soils. The cuttings were transplanted in pots after complete sprouting (15 days). Hibiscus seedlings having 2-3 leaves were used for further experiments.

\section{B. Tabaci}

Bemisia tabaci adults were collected in Guangzhou from cotton plants and reared at the Engineering Research Center of Biological Control, Ministry of Education, South China Agricultural University. Bemisia tabaci was reared in a glasshouse on hibiscus seedlings for two to three generations under the following conditions $26 \pm 1{ }^{\circ} \mathrm{C}, 70 \pm 10 \% \mathrm{RH}$, and 14:10-h light/dark photoperiod.

\section{Parasitoids}

The adult parasitoids (E. bimaculata, E. sophia, and Er. sp. nr. furuhashii) were collected from Engineering Research Center of Biological Control, Ministry of Education, South China Agricultural University, Guangzhou, China. Parasitoids were reared on hibiscus plants infested with second and third instars of B. tabaci. The plants were kept in plexiglass cages $(60 \times 60 \times$ $60 \mathrm{~cm})$ under laboratory conditions at $25 \pm 2{ }^{\circ} \mathrm{C}, 65 \pm$ $10 \% \mathrm{RH}$, and 14:10 (L:D).

\section{Methods}

\section{Host density to the influence of parasitism}

The experimental cages were prepared by pouring water agar solution $(15 \% w / v)$ to petri dishes $(\Phi=3.5 \mathrm{~cm})$. The hibiscus leaves with $B$. tabaci nymphs were placed above the water agar layer and clip cages $(\Phi=3.5 \mathrm{~cm})$ having minute holes were placed above the leaves. The number of second instar B. tabaci nymphs was varied while the number of parasitoid females (E. bimaculata, E. sophia, and Er. sp. nr. furuhashii) was held constant. Each treatment contained while two mated parasitoid females while the host density was divided into six levels $(10,20$, 30, 40, 50, 60 individuals). The mated parasitoid females were released and confined in clip cages along with second instar B. tabaci nymphs at different host densities. After $48 \mathrm{~h}$, the parasitoids were removed and nymphs were observed under the stereoscope to record the number of parasitoid eggs laid. Control treatments for each host density were held without parasitoids to obtain an index of natural host materials. There were five replicates for each treatment.

The Holling function response equation (Holling 1959) was used to calculate the number of hosts attacked:

$$
N_{a}=a T_{\frac{r_{N}}{1+a T_{h} N_{0}}}
$$

where

$$
\begin{aligned}
& N_{a} \text { parasite number } \\
& a \text { rate of successful attack } \\
& T_{r} \text { total parasitic time } \\
& N_{0} \text { host density } \\
& T_{h} \text { time of parasiting each host } \\
& \text { Equation (1) was changed to } \\
& \frac{1}{N_{a}}=\frac{1+a T_{h} N_{0}}{a T_{r} N_{0}}=\frac{1}{a T_{r}} \times \frac{1}{N_{0}}+\frac{T_{h}}{T_{r}}
\end{aligned}
$$

When the total parasitic time was $48 \mathrm{~h}$, while $T_{r}=2$, supposing $A=0.5$ Th, $B=1 /(2 a), Y=1 / N_{a}, X=1 / N_{0}$. The estimates of $T_{h}$ and $a$ were obtained by linear regression. The analog modeling was obtained after entering $T_{h}$ and $a$ to Eq. (1). 


\section{Parasitoid density to the influence of itself parasitism}

The same exposure techniques as described above were used, except the number of parasitoids was varied, with the density of host nymphs held constant. Each treatment contained $1,2,3,4,5,6,7$, or 8 mated parasitoid females ( $<2$ days old) while host density was held constant at 80 nymphs per treatment. A control treatment was held without exposure to parasitoids. After $48 \mathrm{~h}$, the parasitoids were removed and nymphs were observed under the stereoscope to record the number of parasitoid eggs laid. When discovered two or more parasitoid eggs in one whitefly nymph, they were treated as one egg. There were five replicates for each treatment.

The effects of increasing parasitoid density on searching efficiency were analyzed by using Hassell and Varley equation (Hassell and Varley 1969):

$$
\log a=\log \mathrm{Q}-m \log \text { Por } a=Q P^{-m}
$$

where

$a$ discover domain

$m$ mutual interference coefficient

$P$ parasite density

$Q$ search constant

The attack rate $(a)$ was calculated as:

$$
a=1 / P \ln (N / S)
$$

where

$S$ survival host quantity

$N$ total host quantity

Supposing $\ln E=\mathrm{Y}, \ln Q=\mathrm{A},-m=\mathrm{B}, \ln P=\mathrm{X}$, then Hassell-Varley model was calculated by linear regression.

\section{Data analysis}

Data were analyzed using analysis of variance (ANOVA), and means were separated using Tukey's studentized range test. All the data analyses were performed by using SAS 8.01 software (SAS Institute 2000).

\section{Results and discussion}

Effects of constant parasitoid density with varying host

\section{densities on parasitism}

The percentage of parasitism by E. sophia was not significantly affected by different whitefly densities. The highest rate of parasitism by E. sophia (12.00\%) was observed when the host density was 10 individuals per treatment while the lowest rate of parasitism (8.00\%) was observed for host density of 50 individuals per treatment (Table 1). The percentage of parasitism by $E$. bimaculata was significantly affected by different whitefly densities. The highest rate of parasitism by $E$. bimaculata (18.00\%) was observed when the host density was 10 individuals per treatment while the
Table 1 Parasitism rate of parasitoid in different density Bemisia tabaci nymph

\begin{tabular}{llll}
\hline Host density & \multicolumn{3}{l}{ Parasitism (\%) $(\mathrm{M} \pm \mathrm{SE})$} \\
\cline { 2 - 4 } & E. sophia & E. bimaculata & Er. sp. nr. furuhashii \\
\hline 10 & $12.00 \pm 3.35 \mathrm{a}$ & $18.00 \pm 3.35 \mathrm{a}$ & $32.00 \pm 3.35 \mathrm{a}$ \\
20 & $9.00 \pm 0.89 \mathrm{a}$ & $14.00 \pm 1.67 \mathrm{ab}$ & $19.00 \pm 2.61 \mathrm{~b}$ \\
30 & $10.00 \pm 1.63 \mathrm{a}$ & $12.00 \pm 1.52 \mathrm{ab}$ & $25.33 \pm 2.76 \mathrm{ab}$ \\
40 & $9.00 \pm 1.14 \mathrm{a}$ & $10.50 \pm 0.84 \mathrm{~b}$ & $23.00 \pm 1.10 \mathrm{~b}$ \\
50 & $8.00 \pm 0.57 \mathrm{a}$ & $9.60 \pm 0.88 \mathrm{~b}$ & $24.00 \pm 2.33 \mathrm{ab}$ \\
60 & $8.33 \pm 0.47 \mathrm{a}$ & $10.33 \pm 0.99 \mathrm{~b}$ & $25.67 \pm 2.14 \mathrm{ab}$ \\
\hline
\end{tabular}

Means in column with the same letter are not significantly different at 0.05 levels (Tukey's HSD test)

lowest rate of parasitism (10.33\%) was observed for host density of 50 individuals per treatment (Table 1). The rate of parasitism observed for host densities of 40, 50, and 60 individuals per treatment was significantly similar to each other. The rate of parasitism observed for Er. sp. nr. furuhashii was significantly affected by different whitefly densities. The highest rate of parasitism by Er. sp. nr. furuhashii $(32.00 \%)$ was observed. When the host density was 10 individuals per treatment while the lowest rate of parasitism (19.00\%) was observed for host density of 20 individuals per treatment (Table 1).

The number of $B$. tabaci nymphs parasitized by $E$. sophia were significantly increased as the whitefly densities increased. The number of $B$. tabaci nymphs parasitized was lowest (1.20) for host density of 10 individuals per treatment while highest number of $B$. tabaci nymphs parasitized (5.00) was observed for host density of 60 individuals per treatment (Table 2). The expected number of $B$. tabaci nymphs parasitized by $E$. sophia at

Table 2 Parasitic function of parasitoid in different density Bemisia tabaci nymph

\begin{tabular}{llll}
\hline \multirow{2}{*}{ Host density } & \multicolumn{3}{l}{ Quantity which parasitized $(\mathrm{M} \pm \mathrm{SE})$} \\
\cline { 2 - 4 } & E. sophia. & E. bimaculata & $\begin{array}{l}\text { Er. sp. nr. } \\
\text { furuhashii }\end{array}$ \\
\hline 10 & $1.20 \pm 0.33 \mathrm{c}$ & $1.80 \pm 0.33 \mathrm{~d}$ & $3.20 \pm 0.33 \mathrm{~d}$ \\
& $(1.16)$ & $(1.77)$ & $(2.94)$ \\
20 & $1.80 \pm 0.18 \mathrm{c}$ & $2.80 \pm$ & $3.80 \pm 0.52 \mathrm{~d}$ \\
& $(2.09)$ & $0.33 \mathrm{~cd}(2.93)$ & $(5.30)$ \\
30 & $3.00 \pm 0.48 \mathrm{~b}$ & $3.60 \pm 0.46 \mathrm{bc}$ & $7.60 \pm 0.83 \mathrm{c}$ \\
& $(2.85)$ & $(3.76)$ & $(7.24)$ \\
40 & $3.60 \pm 0.46 \mathrm{~b}$ & $4.20 \pm 0.33 \mathrm{bc}$ & $9.20 \pm 0.44 \mathrm{c}$ \\
& $(3.47)$ & $(4.37)$ & $(8.87)$ \\
50 & $4.00 \pm$ & $4.80 \pm 0.44 \mathrm{~b}$ & $12.00 \pm 1.17 \mathrm{~b}$ \\
& $0.28 \mathrm{ab}(4.01)$ & $(4.85)$ & $(10.24)$ \\
60 & $5.00 \pm 0.28 \mathrm{a}$ & $6.20 \pm 0.59 \mathrm{a}$ & $15.40 \pm 1.28 \mathrm{a}$ \\
& $(4.46)$ & $(5.23)$ & $(11.42)$ \\
\hline
\end{tabular}

Means in column with the same letter are not significantly different at 0.05 levels (Tukey's HSD test) 
different host densities was calculated by the following regression equation

$$
Y=0.09680+7.62947 X
$$

The actual and expected number of B. tabaci nymphs parasitized by $E$. sophia were similar to each other for host densities of 10,30, 40, and 50 individuals per treatment while actual number of $B$. tabaci nymphs parasitized by E. sophia for host densities of 20 , and 60 individuals per treatment were higher than the expected number of $B$. tabaci nymphs parasitized by $E$. sophia (Fig. 1a).

The number of $B$. tabaci nymphs parasitized by $E$. bimaculata were significantly increased as the whitefly densities increased. The number of B. tabaci nymphs parasitized was lowest (1.80) for host density of 10 individuals per treatment while highest number of $B$. tabaci nymphs parasitized (6.20) was observed for host density
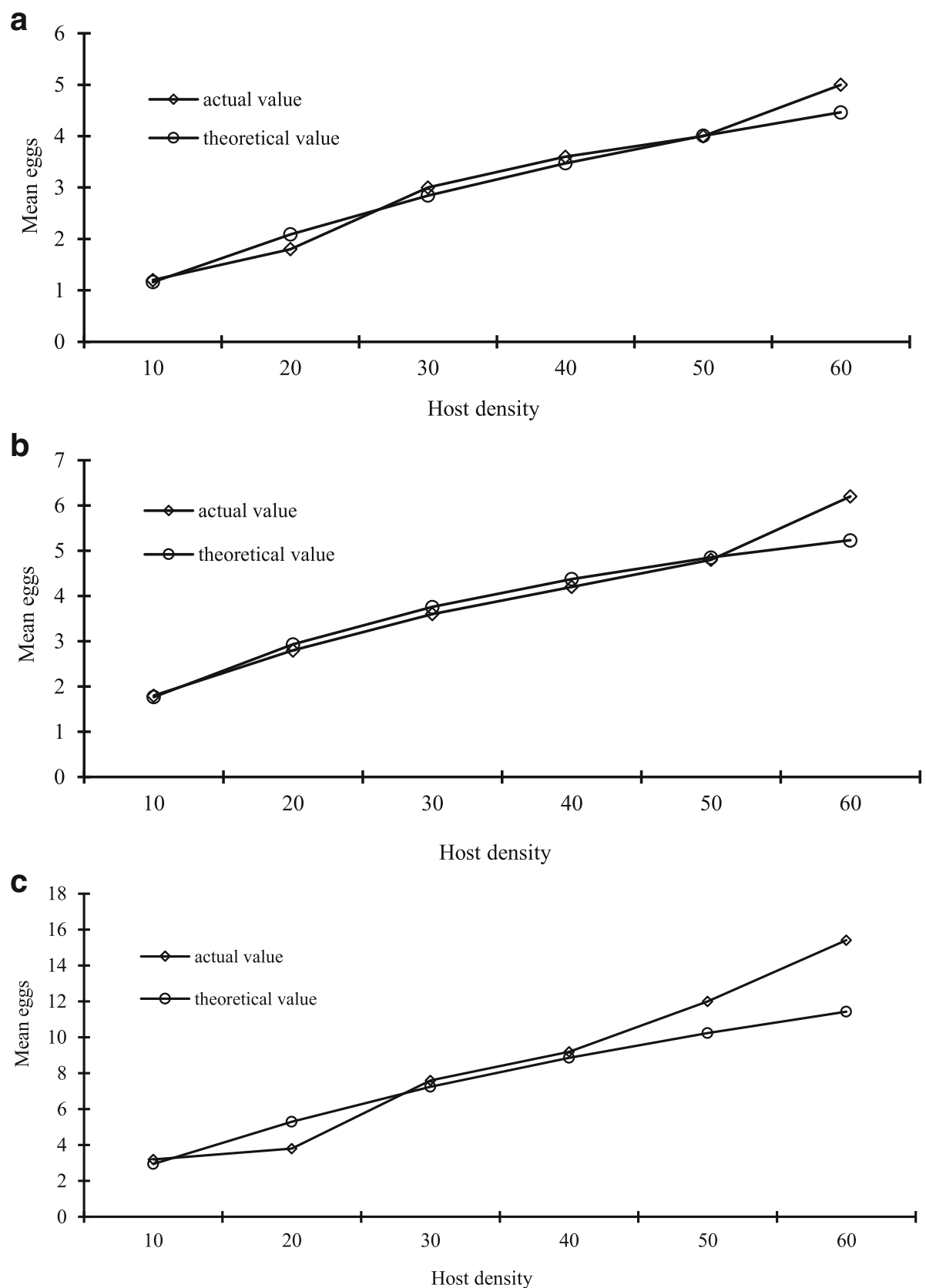

Fig. 1 Comparison of the actual and expected number of whitefly nymphs parasitized by three parasitoid species. a E. sophia. b E. bimaculata. c Er. sp. nr. furuhashii 
of 60 individuals per treatment (Table 2). The expected number of $B$. tabaci nymphs parasitized by E. sophia at different host densities was calculated by the following regression equation

$$
Y=0.11627+4.49220 X
$$

The actual number of $B$. tabaci nymphs parasitized by $E$. bimaculata was lower than the expected number of $B$. tabaci nymphs parasitized by E. sophia for host densities of 20,30, and 40 individuals per treatment while actual number of $B$. tabaci nymphs parasitized by $E$. bimaculata for host densities of 10, and 60 individuals per treatment were higher than the expected number of B. tabaci nymphs parasitized by E. sophia (Fig. 1b).

The number of B. tabaci nymphs parasitized by Er. sp. nr. furuhashii was also significantly increased as the whitefly densities increased. The number of $B$. tabaci nymphs parasitized was lowest (3.20) for host density of 10 individuals per treatment while highest number of $B$. tabaci nymphs parasitized (15.40) was observed for host density of 60 individuals per treatment (Table 2). The expected number of B. tabaci nymphs parasitized by $E$. sophia at different host densities was calculated by the following regression equation

$$
Y=0.03686+3.03285 X
$$

The actual number of $B$. tabaci nymphs parasitized by $E r$. sp. nr. furuhashii for different densities were higher than the expected number of $B$. tabaci nymphs parasitized by Er. sp. nr. furuhashii (Fig. 1b).

The different parameters of functional response model such as rate of successful attack (a) and time spent for parasitizing each host $\left(T_{h}\right)$ for different parasite species were calculated from the following equations:

$$
\begin{aligned}
& \text { E.sophia }=\frac{0.0655 T_{r} N_{0}}{1+0.0127 N_{0}}\left(R^{2}=0.9739\right) \\
& \text { E.bimaculata }=\frac{0.1113 T_{r} N_{0}}{1+0.0259 N_{0}}\left(R^{2}=0.9852\right) \\
& \text { Er.sp.nr.furuhashii }=\frac{0.1649 T_{r} N_{0}}{1+0.0122 N_{0}} \quad\left(R^{2}=0.8640\right)
\end{aligned}
$$

The highest rate successful attack (0.1649) was observed for Er. sp. nr. furuhashii while the rate of successful attack observed for E. bimaculata was lowest with a mean value of 0.0655 . The longest time spent for parasitizing host (0.2325) was observed for E. bimaculata whereas the time spent for parasitizing host by $E r$. sp. nr. furuhashii needed was the shortest with mean value of 0.0737 (Table 3). According to the function response Eq. (1), when host density $N_{0}$ was infinite, and the parasitic upper limit was $T_{r}=1, N_{a}$, the highest
Table 3 Function response parameter of parasitoids in Bemisia tabaci nymph

\begin{tabular}{lllll}
\hline Parasitoids & $a$ & $T_{h}$ & $R^{2}$ & Theoretical value \\
\hline Encarsia sophia & 0.0655 & 0.1936 & 0.9739 & 5.1653 \\
En.bimaculata & 0.1113 & 0.2325 & 0.9852 & 4.3011 \\
Er. sp. nr. furuhashii & 0.1649 & 0.0737 & 0.8640 & 13.5685
\end{tabular}

theoretical value of the whitefly nymph parasitized by each parasitoid in 1 day, was obtained. The theoretical value observed for Er. sp. nr. furuhashii was the highest with the mean value of 13.5685 whereas the lowest theoretical value (4.3011) was observed for E. bimaculata (Table 3).

Our results showed that the parasitic ability of different species under a certain parasitoid density condition was enhanced along with the whitefly density increasing. These results are similar to parasitic behavior observed by Huang et al. (1996) and Zhang et al. (2005) for other parasitoid species like Trichogramma sp. and the Aphidius gifuensis. Zhang et al. (2005) observed highest parasitic ability of two different Trichogramma species when the parasitoid to host ratio was 1:3. Wang and $\mathrm{Li}$ (1996) observed an increase A. gifuensis fecundity with increase in host density until the host density reached 40 individuals/female. The fecundity of parasitoid ranged between 493.3 and 587.5 eggs when host density was higher than 40 individuals/female. In another experiment, Huang et al. (1996) observed a similar increase in the rate of parasitism when single Trichogramma females were reared on different densities of rice moth egg. Furthermore, the parasitism rate was also increased with increasing host density.

Avilla and Albajes (2011) discovered that offspring sex ratio had no influence on parasitic ability and reproduction of parasitoid Opius concolor; however, the host density had certain influences on the parasitic behavior. When the host density was high or low, major offspring of parasitoids were females while at medium density, the majority offspring were male.

\section{Effects of constant host density with varying parasitoid densities on parasitism}

The number of eggs laid by mated females of E. sophia was significantly affected by parasitoid densities. The number of eggs laid by $E$. sophia females increased (from 0.20 to 2.67 ) with increasing parasitoid densities (from 1 to 3 mated females per 60 host nymphs) whereas a decrease in female fecundity was observed as the parasitoid density increased from 3 to 8 mated females per 80 host nymphs (Table 4). The change in parasitoid densities also caused significant variations in the rate of parasitism. The rate of parasitism by E. sophia females increased (from 0.25 to $3.33 \%$ ) with increasing parasitoid 
Table 4 Parasitic function of the different density Encarsia sophia on Bemisia tabaci nymph ( \pm \pm SE)

\begin{tabular}{llllll}
\hline Host density & Parasitoid density & Eggs laid & Parasitism (\%) & $\begin{array}{l}a \\
\text { Actual value }\end{array}$ & $\begin{array}{l}a \\
\text { Theoretic value }\end{array}$ \\
\hline 60 & 1 & $0.20 \pm 0.18 \mathrm{~b}$ & $0.25 \pm 0.22 \mathrm{~b}$ & 0.0025 & 0.0156 \\
60 & 2 & $2.40 \pm 0.68 \mathrm{a}$ & $3.00 \pm 0.86 \mathrm{a}$ & 0.0309 & 0.0198 \\
60 & 3 & $2.67 \pm 0.41 \mathrm{a}$ & $3.33 \pm 0.51 \mathrm{a}$ & 0.0351 & 0.0228 \\
60 & 4 & $2.45 \pm 0.51 \mathrm{a}$ & $3.06 \pm 0.64 \mathrm{a}$ & 0.0327 & 0.0252 \\
60 & 5 & $2.44 \pm 0.48 \mathrm{a}$ & $3.05 \pm 0.60 \mathrm{a}$ & 0.0331 & 0.0272 \\
60 & 6 & $1.47 \pm 0.24 \mathrm{ab}$ & $1.83 \pm 0.30 \mathrm{ab}$ & 0.0194 & 0.0290 \\
60 & 7 & $0.74 \pm 0.12 \mathrm{~b}$ & $0.93 \pm 0.15 \mathrm{~b}$ & 0.0096 & 0.0306 \\
60 & 8 & $0.50 \pm 0.11 \mathrm{~b}$ & $0.63 \pm 0.13 \mathrm{~b}$ & 0.0064 & 0.0320
\end{tabular}

Means in column with the same letter are not significantly different at 0.05 levels (Tukey's HSD test)

densities (from 1 to 3 mated females per 80 host nymphs) whereas a decrease in the rate of parasitism was observed as the parasitoid density increased from 3 to 8 mated females per 60 host nymphs (Table 4). The mutual interference analysis performed trough Hassel-Varley model resulted in the following equation

$$
a=0.0156 P^{0.3457}
$$

The search constant calculated from above analysis was 0.0156 while the value of mutual interference parameter was 0.345 . The actual and calculated values for rate of attack (a) were different from each other (Table 4$)$. The actual values of attack rate $(a)$ of $E$. sophia females increased (from 0.025 to 0.0351 with increasing parasitoid densities (from 1 to 3 mated females per 60 host nymphs) whereas a decrease in values of attack rate was observed as the parasitoid density increased from 3 to 8 mated females (Table 4).

The number of eggs laid by mated females of E. bimaculata was significantly affected by parasitoid densities. The number of eggs laid by $E$. bimaculata females increased (from 0.60 to 2.08) with increasing parasitoid densities (from 1 to 5 mated females per 60 host nymphs) whereas a decrease in female fecundity was observed as the parasitoid density increased from 4 to 8 mated females (Table 5). The change in parasitoid densities also caused significant variations in rate of parasitism. The rate of parasitism by E. bimaculata females increased (from 0.75 to $2.60 \%$ ) with increasing parasitoid densities (from 1 to 5 mated females per 60 host nymphs) whereas a decrease in rate of parasitism was observed as the parasitoid density increased from 5 to 8 mated females per 80 host nymphs (Table 5). The mutual interference analysis performed trough Hassel-Varley model resulted in the following equation

$$
a=0.0089 P^{0.4325}
$$

The search constant calculated from above analysis was 0.0089 while the value of mutual interference parameter was 0.4325 . The actual values of attack rate $(a)$ were different from each other (Table 5). The actual values of attack rate $(a)$ of $E$. bimaculata females increased (from 0.0075 to 0.0791 ) with increasing parasitoid densities (from 1 to 5 mated females per 80 host nymphs) whereas a decrease in values of attack rate was observed as the parasitoid density increased from 5 to 8 mated females (Table 5).

Table 5 Parasitic function of the different density E. bimaculata on Bemisia tabaci nymph $(\mathrm{M} \pm \mathrm{SE})$

\begin{tabular}{llllll}
\hline Host density & Parasitoid density & Eggs laid & Parasitism (\%) & $\begin{array}{l}a \\
\text { Actual value }\end{array}$ & $\begin{array}{l}a \\
\text { Theoretic value }\end{array}$ \\
\hline 60 & 1 & $0.60 \pm 0.36 \mathrm{c}$ & $0.75 \pm 0.45 \mathrm{c}$ & 0.0075 & 0.0089 \\
60 & 2 & $0.80 \pm 0.11 \mathrm{bc}$ & $1.00 \pm 0.14 \mathrm{bc}$ & 0.0101 & 0.0120 \\
60 & 3 & $1.33 \pm 0.13 \mathrm{abc}$ & $1.67 \pm 0.17 \mathrm{abc}$ & 0.0171 & 0.0143 \\
60 & 4 & $1.60 \pm 0.19 \mathrm{ab}$ & $2.00 \pm 0.24 \mathrm{ab}$ & 0.0208 & 0.0162 \\
60 & 5 & $2.08 \pm 0.15 \mathrm{a}$ & $2.60 \pm 0.18 \mathrm{a}$ & 0.0279 & 0.0179 \\
60 & 6 & $1.70 \pm 0.24 \mathrm{a}$ & $2.13 \pm 0.30 \mathrm{a}$ & 0.0227 & 0.0193 \\
60 & 7 & $1.60 \pm 0.39 \mathrm{ab}$ & $2.00 \pm 0.49 \mathrm{ab}$ & 0.0215 & 0.0206 \\
60 & 8 & $0.83 \pm 0.10 \mathrm{bc}$ & $1.03 \pm 0.13 \mathrm{bc}$ & 0.0108 & 0.0219 \\
\hline
\end{tabular}

Means in column with the same letter are not significantly different at 0.05 levels (Tukey's HSD test) 
Table 6 Parasitic function of the different density Er. sp. nr. furuhashii on Bemisia tabaci nymph (M \pm SE)

\begin{tabular}{llllll}
\hline Host density & Parasitoid density & Eggs laid & Parasitism (\%) & $\begin{array}{l}a \\
\text { Actual value }\end{array}$ & $\begin{array}{l}a \\
\text { Theoretic value }\end{array}$ \\
\hline 60 & 1 & $1.40 \pm 0.46 \mathrm{~d}$ & $1.75 \pm 0.57 \mathrm{~d}$ & 0.0177 & 0.0392 \\
60 & 2 & $5.50 \pm 0.47 \mathrm{~b}$ & $6.88 \pm 0.59 \mathrm{~b}$ & 0.0740 & 0.0502 \\
60 & 3 & $7.13 \pm 0.81 \mathrm{a}$ & $8.92 \pm 1.02 \mathrm{a}$ & 0.1038 & 0.0580 \\
60 & 4 & $7.75 \pm 0.24 \mathrm{a}$ & $9.69 \pm 0.31 \mathrm{a}$ & 0.1226 & 0.0643 \\
60 & 5 & $7.36 \pm 0.55 \mathrm{a}$ & $9.20 \pm 0.69 \mathrm{a}$ & 0.1232 & 0.0696 \\
60 & 6 & $3.60 \pm 0.71 \mathrm{c}$ & $4.50 \pm 0.89 \mathrm{c}$ & 0.0525 & 0.0743 \\
60 & 7 & $3.34 \pm 0.25 \mathrm{c}$ & $4.18 \pm 0.31 \mathrm{c}$ & 0.0494 & 0.0785 \\
60 & 8 & $3.10 \pm 0.18 \mathrm{c}$ & $3.88 \pm 0.23 \mathrm{c}$ & 0.0464 & 0.0823
\end{tabular}

Means in column with the same letter are not significantly different at 0.05 levels (Tukey's HSD test)

The number of eggs laid by mated females of Er. sp. nr. furuhashii was significantly affected by parasitoid densities. The number of eggs laid by Er. sp. nr. furuhashii's females increased (from 1.40 to 7.36 ) with increasing parasitoid densities (from 1 to 5 mated females per 60 host nymphs) whereas a decrease in female fecundity was observed as the parasitoid density increased from 4 to 8 mated females (Table 5). The change in parasitoid densities also caused significant variations in the rate of parasitism. The rate of parasitism by Er. sp. nr. furuhashii's females increased (from 1.75 to $9.20 \%$ ) with increasing parasitoid densities (from 1 to 5 mated females per 60 host nymphs) whereas a decrease in the rate of parasitism was observed as the parasitoid density increased from 5 to 8 mated females per 60 host nymphs (Table 5). The mutual interference analysis performed trough Hassel-Varley model resulted in the following equation

$$
a=0.0392 P^{0.3568}
$$

The search constant calculated from above analysis was 0.0362 while the value of mutual interference parameter was 0.3568 . The actual values of attack rate (a) were different from each other (Table 6). The actual values of attack rate (a) of Er. sp. nr. furuhashii's females increased (from 0.0177 to 0.1232 with increasing parasitoid densities (from 1 to 5 mated females per 80 host nymphs) whereas a decrease in values of attack rate was observed as the parasitoid density increased from 5 to 8 mated females (Table 6).

Density of parasitoid can also influence the rate of parasitism. Under a certain host density, density of Opius caricivorae Fischer was high, its parasitic rate and number of eggs laid were reduced gradually showing a good fitting effect of Hassell-Varley model (Gao 2002). In this experiment, in the certain density whitefly situation, parasitic ability of three different parasite species increased with increase in wasp density increasing, but when wasp density achieved a certain degree, the rate of parasitism started to decrease. The variation in number of eggs laid and parasitism rate proved the existence of an interference effect of Eretmocerus sp. nr. furuhashii, Encarsia bimaculata, and Encarsia sophia. These results are similar to the findings of Saljoqi and He (2004) who studied the influence of wasp density on parasitism of corn borer by Trichogramma sp. when wasp was introduced into the rice moth eggs (density was 400) at four different densities (density was 1,2, 4, and 8, respectively). When the density was 8 , the total parasitism rate observed for host density of 8 was higher than other parasitoid densities. The average rate of parasitism per female reduced with increasing wasp densities. When the wasp density increased from 1 to 8 , the average parasitism rate of each female wasp was reduced to nearly one half. Simultaneously, the reproduction of each female also reduced with increasing wasp density which shows that the increasing wasp density reduced the parasitic potency of Trichogramma.

\section{Conclusions}

Our results serve to increase the knowledge about three important parasitoids of whitefly (Er. sp. nr. furuhashii, E. bimaculata, and E. sophia). These results also provide basic information for long-term studies on comparing the relative efficiencies and mutual interference effect of different parasitoid species in sustainable whitefly management programs.

\section{Funding \\ This research was funded by the grants from the Science and Technology Program of Guangzhou, P.R. China (201509010023).}

Availability of data and materials

All the materials and data shown will be available if required by the journal.

Authors' contributions

All authors read and approved the manuscript.

Competing interests

The authors declare that they have no competing interests. 


\title{
Publisher's Note
}

Springer Nature remains neutral with regard to jurisdictional claims in published maps and institutional affiliations.

\begin{abstract}
Author details
${ }^{1}$ Key Laboratory of Bio-Pesticide Innovation and Application, Engineering Research Center of Biological Control, South China Agricultural University, Guangzhou 510640, People's Republic of China. ²Plant Qurantine Lab of Guangdong Inspection and Quarantine Technology Centre, Guangzhou 510623, People's Republic of China.
\end{abstract}

Received: 29 December 2017 Accepted: 10 May 2018

Published online: 20 July 2018

\section{References}

Avilla J, Albajes R (2011) The influence of female age and host size on the sex ratio of the parasitoid opius concolor. Exp Appl 35(1):43-47

Barbosa LF, Marubayashi JM, De Marchi BR, Yuki VA, Pavan MA, Moriones E (2014) Indigenous American species of the Bemisia tabaci complex are still widespread in the Americas. Pest Manag Sci 70(10):1440-1445

De Barro PJ, Liu SS, Boykin LM, Dinsdale AB (2011) Bemisia tabaci: a statement of species status. Annu Rev Entomol 56(1):1-19

Devine GJ, Furlong MJ (2007) Insecticide use: contexts and ecological consequences. Agri Hum Val 24(3):281-306

Gao LX (2002) Biology and ecology of opius caricivorae fischer. Fujian agricultural and forestry university master degree paper, Fujian, pp 1-68

Gerling D, Fried R (2000) Biological studies with Eretmocerus mundus (Hymenoptera: Aphelinidae). J Econ Entomol 87:117-123

Gerling D, Tremblay E, Orion T (1991) Initial stages of vital capsule formation in the Eretmocerus-Bemesia tabaci association. Redia 7(4):411-415

Godfray HCJ, Shimada M (1999) Parasitoids as model organisms for ecologists. Res Popul Ecol 41(1):3-10

Hassell MP, Varley GC (1969) New inductive population model for insect parasites and its bearing on biological control. Nature 223(5211):1133-1137

Holling CS (1959) Some characteristics of simple types of predation and parasitism. Can Entomol 91(7):385-398

Huang SS, Dai ZY, Wu DZ (1996) Studies on the interference efficiency of trichogramma ostrinia. Chinese Bull Entomol 33:108-110

Kirk A. A., L. A. Lacey, J. K. Brown, M. A. Ciomperlik, J. A. Goolsby, D. C., Vacek, L. E. Wendel, B. Napompeth 2000. Variation in the Bemisia tabaci, 1. Species complex (Hemiptera: Alyerodidae) and its natural enemies leading to successful biological control of B. tabaci biotype B in the USA. Bull Entomol Res, 90: 317--327

Liang P, Tian YA, Biondi A, Desneux N, Gao XW (2012) Short-term and transgenerational effects of the neonicotinoid nitenpyram on susceptibility to insecticides in two whitefly species. Ecotoxicology 21(7):1889-1898

Oliveira MRV, Henneberry TJ, Anderson P (2001) History, current status, and collaborative research projects for Bemisia tabaci. Crop Prot 20(9):709-723

Perring TM (2001) The Bemisia tabaci species complex. Crop Prot 20(9):725-737

Qiu B, Ren S, Xiao Y, Mandour NS (2003) Effectiveness of Eretmocerus sp. and Aschersonia aleyrodis in controlling Bemisia tabaci population. Bull Entomol Res 14(14):2251-2254

Revathi K, Chandrasekaran R, Thanigaivel A, Kirubakaran SA, Nathan SS (2014) Biocontrol efficacy of protoplast fusants between Bacillus thuringiensis and Bacillus subtilis against Spodoptera litura Fabr. Arch Phytopathol Plant Prot 47(11):1365-1375

Roudrigues MD, Moreno R, Tellez MM (1994) Eretmocerus mundus (Mercet), Encarsia lutea (Masi) y Encarsia transcera (Timberlake) (Hymenoptera: Aphelinidae) parasitoides de Bemisia tabaci (Homoptera: Alyerodidae) en los cultivos horticolas protegidos almerienses. Biol San Veg Plagas 20:695-702

Saljoqi AUR, He Y (2004) Effect of host and parasite density on trichogramma ostrinae. J of South China Agri Univ 25(3):120-122

SAS Institute (2000) SAS user's guide. Statistics, SAS Institute, Cary, North Carolina, USA

Wang WX, Li QS (1996) Effect of host density on reproductive rate of aphidius gifuensis. Acta Agriculturae Boreali-sinica 11:52-57

Wang Z, Yan H, Yang Y, Wu Y (2010) Biotype and insecticide resistance status of the whitefly Bemisia tabaci from China. Pest Manag Sci 66(12):1360-1366

Zhang F, Tao SX, Wang SQ (2005) The impacts of host species and host density on the parasitizing potentials of the offsprings of two trichogramma species on ostrinia furnacalis eggs. China Biological Control 21:216-217

\section{Submit your manuscript to a SpringerOpen ${ }^{\odot}$ journal and benefit from:}

- Convenient online submission

- Rigorous peer review

- Open access: articles freely available online

- High visibility within the field

- Retaining the copyright to your article

Submit your next manuscript at $\gg$ springeropen.com 